\title{
NON-FUSION APPLICATIONS OF RF AND MICROWAVE
} TECHNOLOGY*

\author{
J. B. O. Caughman, F. W. Baity, T. S. Bigelow, W. L. Gardner, D. J. \\ Hoffman, S. C. Forrester, and T. L. White. \\ Oak Ridge National Laboratory

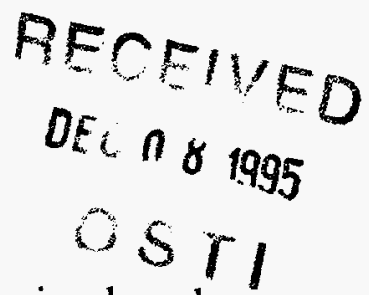

The processing of materials using $\mathrm{rf}$ and/or microwave power is a broad area that has grown significantly in the past few years. We have applied if and microwave technology in the areas of ceramic sintering, plasma processing, and waste processing. The sintering of ceramics in the frequency range of $50 \mathrm{MHz}-28$ $\mathrm{GHz}$ has lead to unique material characteristics compared to materials that have been sintered conventionally. It has been demonstrated that sintering can be achieved in a variety of materials, including alumina, zirconia, silicon carbide, and boron carbide. In the area of plasma processing, progress has been made in the development and understanding of high density plasma sources, including inductively coupled plasma (ICP) sources. The effects of processing conditions on the ion energy distribution at the substrate surface (a critical processing issue) have been determined for a variety of process gases. The relationship between modeling and experiment is being established. Microwave technology has also been applied to the treatment of radioactive and chemical waste. The application of microwaves to the removal of contaminated concrete has been demonstrated. Details of these programs and other potential application areas are discussed.

\section{INTRODUCTION}

The use of $\mathrm{rf}$ and microwave power for fusion plasmas is just one of many useful applications of this technology. Applications range from microelectronics manufacturing to the vulcanization of rubber to food processing. Many of these areas involve the interaction of of microwaves with a material or processing application that can be quite complex and show highly nonlinear behavior that is comparable to fusion applications of if and microwaves. For example, the plasma chemistry involved with microelectronics manufacturing is extremely complex and not well understood in many instances. ORNL has applied some of the technology gained from the fusion program to several areas. These areas include the sintering of ceramics, plasma processing, and the decontamination of concrete.

\section{CERAMIC SINTERING}

A great deal of work has been done in the past ten years with the use of microwaves in the sintering of ceramics $[1,2]$. Sintering is the densification of a

\footnotetext{
* Research sponsored by the U.S. Department of Energy, under contract DEAC05-840R21400 with Martin Marietta Energy Systems, Inc.
} 


\section{DISCLAIMIRR}

Portions of this document may be illegible in electronic image products. Images are produced from the best available original document. 
powder compact to form a dense, solid monolithic body. The powder compact is referred to as a "green body." The green body form is composed of ceramic powder and is often mixed with a binding material that volatilizes at elevated temperatures. It is typically isostatically pressed ( $\geq 30 \mathrm{kpsi})$ and obtains a density of around $50 \%$ of the theoretical density of the powder that makes up the green body. The rest of the volume consists of voids between the powder particles and the binder. In conventional sintering, the green body is placed in a furnace and heated to the sintering temperature. For alumina, this temperature is 1500 $1600^{\circ} \mathrm{C}$. When sintering occurs, the voids are greatly reduced, and the density of the resulting body is nearly $100 \%$ of the density of the powder material.

The advantage of microwave sintering over conventional sintering is related to the volumetric interaction of the electromagnetic fields with the ceramic. This volumetric coupling to the ceramic leads to a higher heating efficiency and faster processing times than those achievable in conventional furnaces. Microwave sintering has typically used $2.45 \mathrm{GHz}$ power, but $915 \mathrm{MHz}, 28 \mathrm{GHz}$, and 4-6 GHz variable frequency supplies have also been used [2]. Microwave sintering has been used in a variety of materials, but it is mostly limited to materials with relatively small volumes and/or low dielectric loss tangents because of the limits of the depth of penetration of the electric field. A new technique that uses lower frequency rf power $(\sim 50 \mathrm{MHz})$ allows the penetration of high loss materials and is described in detail later in this section.

The heating of the ceramic is obtained by the coupling of the electric field to the dielectric losses of the material. The amount of power per unit volume that is coupled into the ceramic by electric fields is given by [3]

$$
P=\frac{1}{2} \omega \varepsilon(\tan \delta) E^{2}
$$

where $\omega$ is the frequency, $\varepsilon$ is the dielectric constant, $\tan \delta$ is the loss tangent, and $E$ is the electric field. Both the dielectric constant and the loss tangent are functions of temperature and generally increase with temperature. In the typical microwave range, the frequency is high $\left(10^{10} \mathrm{~Hz}\right)$, the electric field is low $(<100$ $\mathrm{V} / \mathrm{cm}$ ), and the loss tangent is generally high $\left(10^{-2}\right)$.

The size limitation for volumetric heating with electric fields is related to the dielectric properties of the material. The distance that the electric field can penetrate a ceramic is given by [4]

$$
x=\frac{\sqrt{2\left(1+\sqrt{1+\tan ^{2} \delta}\right)}}{\omega \tan \delta \sqrt{\mu_{0} \varepsilon^{\prime}}}
$$

where $x$ is the $e$-folding penetration depth, $\mu_{0}$ is the material permeability (assumed free space), and $\varepsilon^{\prime}$ is the permittivity. An example of the penetration depth as a function of frequency is shown in Fig. 1 for boron carbide $\left(\mathrm{B}_{4} \mathrm{C}\right)$ at $1100^{\circ} \mathrm{C}$ and alumina at $23^{\circ} \mathrm{C}$. Since only low frequencies can penetrate high-loss materials (such as $\mathrm{B}_{4} \mathrm{C}$ ), the rf range of frequencies has been explored for use in sintering. 
The advantage of rf sintering over microwave sintering is related to the higher electric fields and greater sample penetration depth obtained with sintering at $\mathrm{rf}$ frequencies. For rf sintering, the frequency is lower $\left(<10^{8} \mathrm{~Hz}\right)$, the loss tangent is generally lower $\left(10^{-3}\right)$, and the electric field is higher (1000 $\mathrm{V} / \mathrm{cm}$ ). Thus, compared to most microwave techniques, rf absorption is reduced by three to four orders of magnitude in the product of frequency and loss tangent, but electric field effects are up to four orders of magnitude higher because the

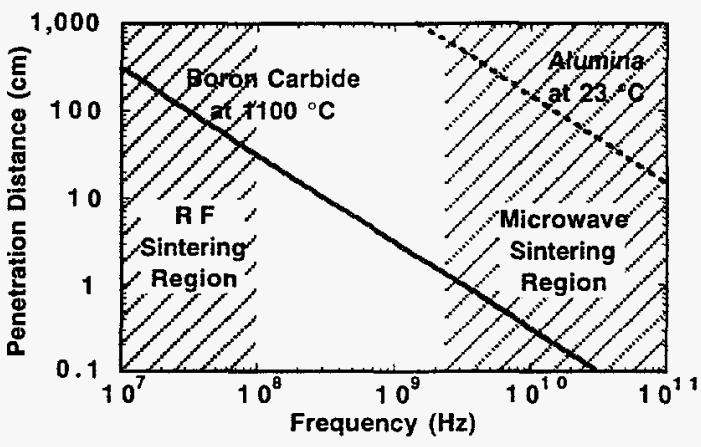

Fig. 1 Depth of electric field penetration as a function of frequency for a low-loss and a high-loss material. field is $10-100$ times greater. Therefore, rf sintering has roughly the same total power deposition as microwave sintering but has a much higher electric field, and it can be used to determine whether the critical component of electromagnetic energy sintering is the strength of the electric field or the value of the excitation frequency. In contrast to microwave sintering, the wavelengths of the rf waves are considerably greater than the dimensions of the sintering cavity, and generally results in a single permissible mode of operation with a uniform electric field. The rf sintering cavity consists of a quarter-wave coaxial resonator with the center conductor grounded at one end and an electrode placed at the high voltage end. The sample to be sintered is placed at the high voltage (high electric field) end of the cavity. Details of the rf sintering furnace are given in ref

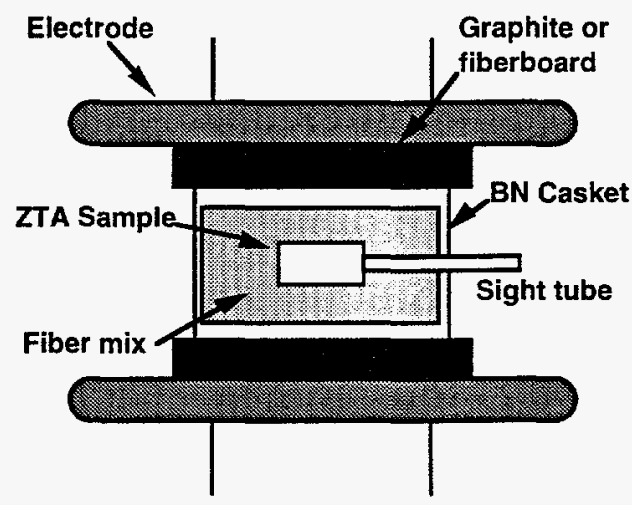
[5].

For both microwave and rf sintering, the sintering specimen is typically packed in insulation inside a casket. A typical casket assembly is shown in Fig. 2. The casket material is commonly a high temperature, low absorbing material, such as boron nitride. The material to be sintered is placed inside the casket and surrounded with some type of insulating powder or fiber. Alumina and/or zirconia loose fiber or fiber board are common materials. The temperature of the sample is either measured with a shrouded thermocouple or is measured optically with a pyrometer using a fiber optic or a sight tube. 
The density as a function of processing temperature has been determined for the rf sintering of zirconia-toughened alumina (ZTA). This material was chosen because of its high hardness and for comparisons with previously published [6] results. The samples were composed of $40 \mathrm{wt} \%$ zirconia (Tosoh TZ-2Y) and 60 wt \% alumina (Sumitomo AKP 50) and prepared as previously described in ref [6]. The mass of the samples were typically $18-20 \mathrm{~g}$. The rf processing frequency was 52 $\mathrm{MHz}$, and the processing atmosphere was flowing nitrogen at slightly over $1 \mathrm{~atm}$ of pressure. The samples were arranged in a casket as shown in Fig. 2. They were placed inside a $7.62 \mathrm{~cm}$ diameter, $4.76 \mathrm{~cm}$ thick boron nitride casket and surrounded by a $50 \mathrm{wt} \%$ mixture of alumina and zirconia fiber (Zircar). The temperature of the sample was measured optically by looking at the sample through a sight tube.

Heating rates and power levels were dependent on the temperature of the sample/casket assembly. A plot of if power and temperature as a function of time

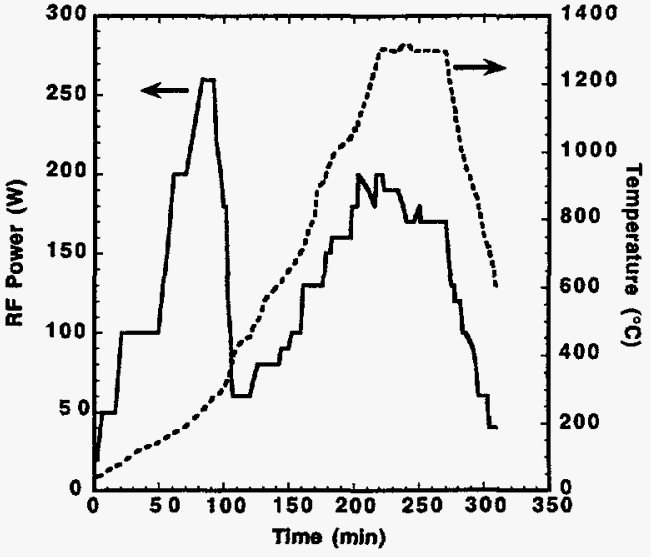

Fig. 3 RF power and sample temp during a ZTA sintering run.

for a typical run is shown in Fig. 3. Initial heating rates of the sample were roughly $2.5^{\circ} \mathrm{C} / \mathrm{min}$ until dielectric relaxation occurred, which was between 250 $350^{\circ} \mathrm{C}$. After this point, the power required to maintain the temperature dropped, and the heating efficiency increased significantly because of the increase in the loss tangent with temperature. Heating rates increased to roughly $10^{\circ} \mathrm{C} / \mathrm{min}$ up to the desired temperature. The samples were held at the target temperature for 1 hour.

The density as a function of temperature is shown in Fig. 4. For comparison, the sintering curve for conventional processing [6] is also shown in the figure. The dependence of the density on temperature for the rf sintered samples is similar to the temperature dependence of the conventionally sintered material. The final densification was $>99 \%$ for the higher temperature samples.

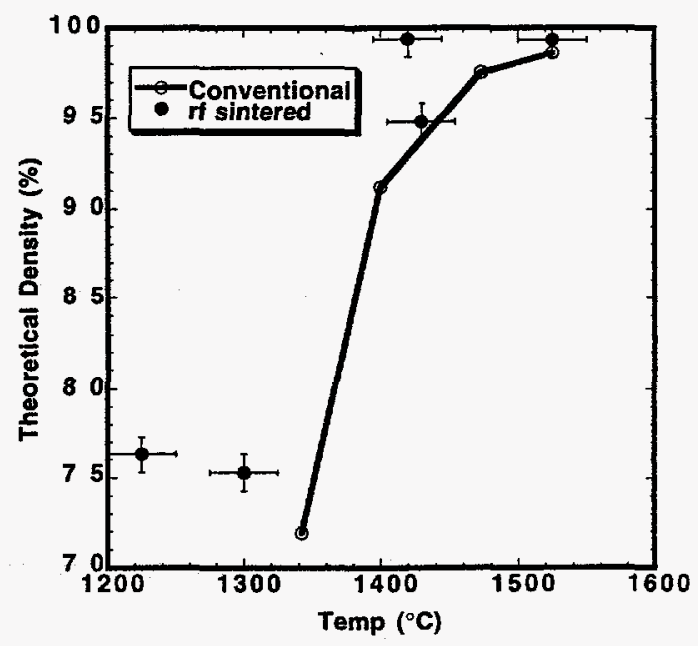

Fig. 4 Density as a function of processing temperature for rf sintered ZTA. 
Processing with rf has also been used to sinter alumina [5]. This work is part a program to evaluate the ballistic performance of ceramics for tank armor applications. Earlier work found that annealing pre-sintered alumina tiles (15.2 $\mathrm{cm} \times 15.2 \mathrm{~cm} \times 2-5 \mathrm{~cm}$ ) with $28 \mathrm{GHz}$ microwaves improved the ballistic performance of the tiles by up to $18 \%$ [7]. Current efforts are focusing on producing $10 \mathrm{~cm}$ square tiles by sintering with of at $37 \mathrm{MHz}$. Ballistic tests are planned for later this year.

A number of carbide materials have been processed at rf frequencies. Application areas range from high temperature turbine blades to tank armor. These materials emphasizes one of the advantages of rf sintering, which is the ability of the electric field to penetrate high-loss materials such as boron carbide and silicon carbide. These compounds have been heated to $>2000{ }^{\circ} \mathrm{C}$ and sintered to up to $97 \%$ of theoretical density. An insulation package that can handle temperature in excess of $2000{ }^{\circ} \mathrm{C}$ is an issue, but progress is being made [8]. Other carbides, such as tungsten carbide and titanium carbide have either been sintered or annealed. The results are summarized in Table I.

Table I. Carbide and other materials processed to date.

\begin{tabular}{|l|c|c|c|l|}
\hline \multicolumn{1}{|c|}{ Material } & Process & Temp $\left({ }^{\circ} \mathrm{C}\right)$ & $\%$ Density & \multicolumn{1}{c|}{ Comments } \\
\hline $\begin{array}{l}\text { Silicon carbide } \\
\text { (Cercom) }\end{array}$ & sinter & $\geq 2000$ & 84 & $\begin{array}{l}12.5 \text { g sample (Limited by } \\
\text { current insulation scheme) }\end{array}$ \\
\hline $\begin{array}{l}\text { Boron carbide } \\
(2.5 \text { wt \% C [9]) }\end{array}$ & sinter & $>1700$ & 97 & $\begin{array}{l}\text { Repeatability limited by } \\
\text { current insulation scheme }\end{array}$ \\
\hline $\begin{array}{l}\text { Zirconia } \\
\text { Titanium carbide }\end{array}$ & anneal & 1500 & - & 3 ! g sample \\
\hline $\begin{array}{l}\text { Tungsten carbide } \\
\text { (6 wt \% Co) }\end{array}$ & sinter & 1500 & 97 & 14 g sample \\
\hline
\end{tabular}

\section{PLASMA PROCESSING}

The application of plasmas to material processing has grown enormously in the past twenty years. One of the largest application areas has been microelectronics manufacturing. There is a growing interest to process with high density plasma sources. Compared to conventional parallel plate if systems, these sources have the advantage of shorter processing times and higher throughput because of their higher ion flux. Since they operate at low pressures ( $<20 \mathrm{mTorr}$ ), the plasma sheath that forms on the surface of the wafer is collisionless, and the ions bombard the surface with a highly directional velocity. This high directivity allows for anisotropic etching or deposition and smaller feature size.

Inductively coupled plasma (ICP) sources are one of several different high density plasma sources being considered for microelectronics fabrication, such as ECR and helicon wave sources. ICP sources are relatively simple, compact, do not require external solenoid magnetic fields, and have a high efficiency in terms of amps of ion current per watt of input power. Several papers have been published $[10,11]$ on the general operation, characterization, modeling, and uses of these sources. 
While the use of this type of plasma source in increasing, one area that has not been studied extensively is the energy of the ions hitting the surface of the substrate. The ion energy distribution (IED) is very important for several processing issues in both etching and deposition. For etching, the ability to selectively etch one material while not significantly affecting another material is important. For example, the process window for having high silicon etching and low silicon dioxide etching can be small and is ion energy dependent.[12] For deposition, the energy of the ionized reactants incident on the surface as the film is deposited can be critical to the film

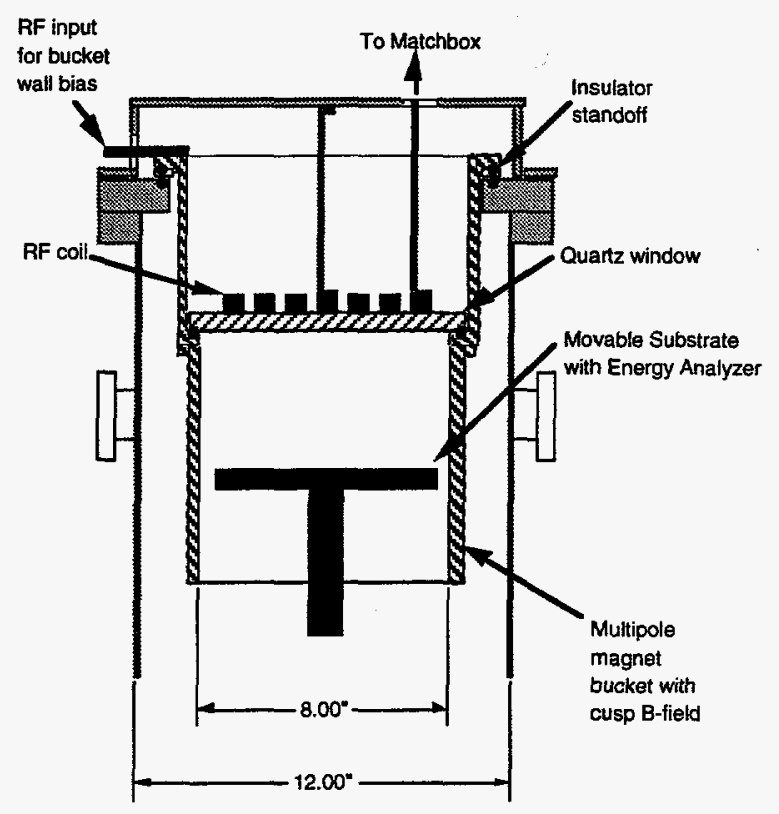

Fig. 5 Schematic of ICP source stoicheometry.[13] Damage to the thin film by energetic ions is a factor that affects both etching and deposition. Hence, the effect of operating parameters in the source on the IED at the substrate surface needs to be determined.

These effects have been studied using a planar type ICP. The apparatus is shown schematically in Fig. 5. The source consists of a planar spiral coil (17.5 $\mathrm{cm}$ diam) that is separated from the chamber by a $2.54 \mathrm{~cm}$ thick quartz plate. The plasma region is surrounded by a multipole magnet bucket (stainless steel) containing twelve columns of permanent magnets arranged to give a cusp magnetic field. The bucket has an i.d. of $20 \mathrm{~cm}$ and is $20 \mathrm{~cm}$ long. The bucket is electrically isolated from the rest of the system and can be floated, grounded, or biased with dc or if power. The effect of changing this boundary condition will be discussed below. Unless noted otherwise, the bucket was grounded during the experiments. The IED was measured with a gridded retarding field analyzer embedded in the substrate. Other system details are given in ref. [14].

The variation of several plasma parameters as a function of pressure is shown in Fig. 6 for an argon plasma with $200 \mathrm{~W}$ of rf power. As the operating pressure decreases, the electron

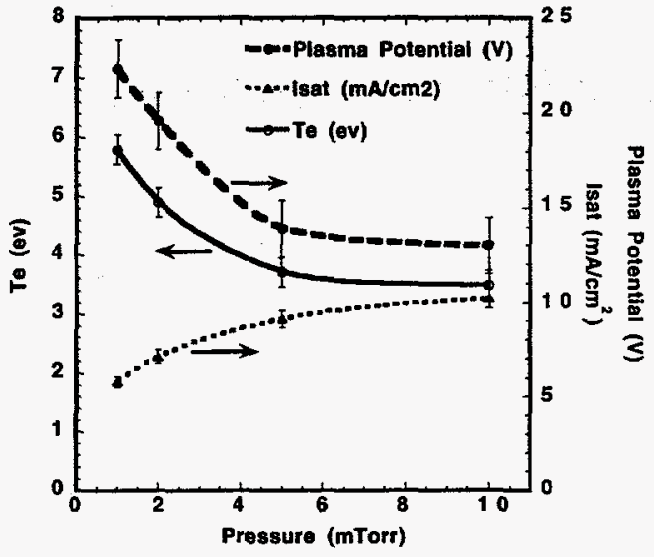

Fig. 6 The dependence of several plasma parameters as a function of pressure. 
temperature and the plasma potential increase, while the ion current decreases. These results are similar to other published results for these types of plasma sources [11]. The energy of the ions hitting the substrate surface also increase as the pressure decreases, as shown in Fig. 7. The increase in ion energy is caused the by ions being accelerated though the plasma sheath that forms at the substrate surface. The ion energy distribution shifts to higher energies and is similar to the shift in plasma potential as the pressure decreases. The distributions for argon are fairly narrow. For other gases, such as hydrogen and helium, the IED can be much broader $(>50$ $\mathrm{eV}) \cdot[14]$

Changing the boundary conditions on the bucket wall can also have an effect on the ion energy distribution. The potential that is applied to the wall has an effect on the potential of the plasma. Several experiments have been run where the plasma is formed by the induction coil while the wall in contact with the plasma was separately biased. Applying a rf bias at $2 \mathrm{MHz}$ on the wall causes an increase in the oscillation of the plasma potential. This oscillation in the plasma potential has an effect on the plasma sheath and the IED hitting the surfaces in contact with the plasma. The IED at the substrate as a function of wall bias potential is shown in Fig. 8. For these data, the target plasma was argon at 2 mTorr with $200 \mathrm{~W}$ of $\mathrm{rf}$ power from the induction coil. The IED broadens as the wall potential increases, implying that the sheath potential oscillation is also increasing. This increase in the flux of higher energy ions can be used in an ion assisted insitu cleaning process of the chamber surfaces in contact with the plasma. Such a cleaning step may be useful to prevent the build-up of thin films on the walls of a plasma tool used in a deposition process for Fig. 8 microelectronics manufacturing.

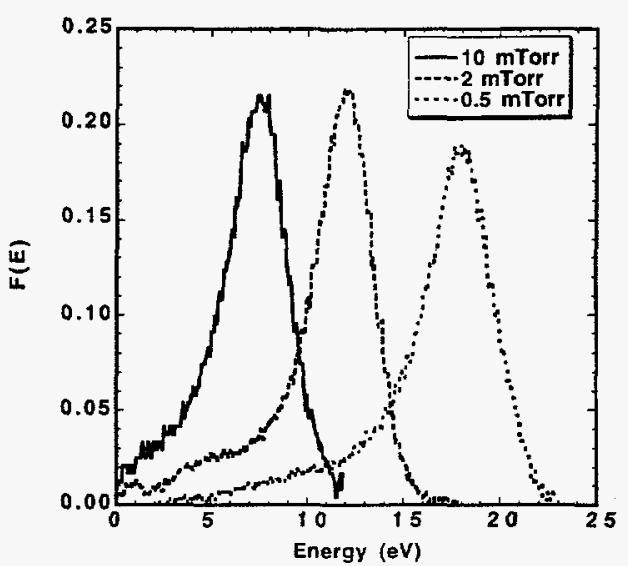

Fig. 7 Ion energy distributions at the substrate surface as a function of pressure

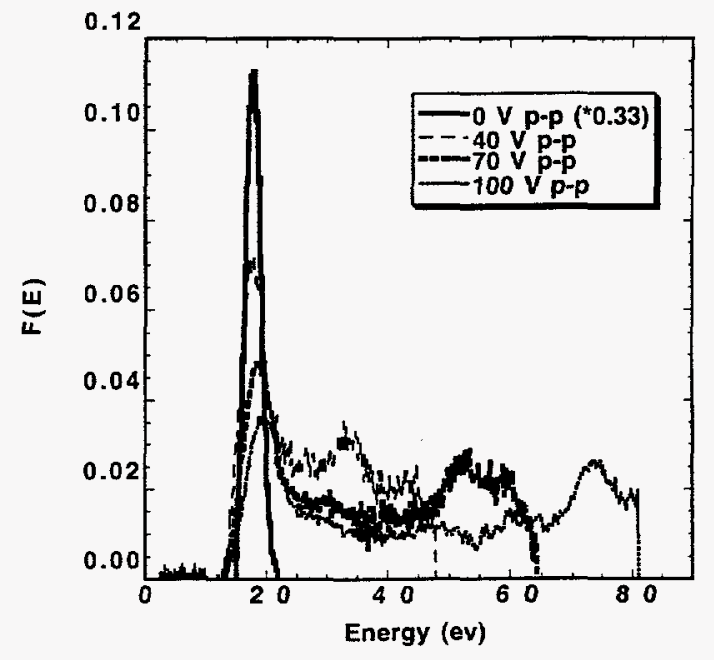

Fig. 8 IED at the substrate as a function of wall bias voltage. 
The cleaning of these surfaces between deposition steps can help to reduce the amount of cracking and flaking of the film deposited on chamber walls that can lead to dust generation and contamination of the wafer being processed.

\section{CONCRETE DECONTAMINATION}

Several facilities that handle radioactive materials have some residual radioactive contamination of concrete structures that needs to be removed. For most cases, the degree of contamination is usually restricted to the surface layer $(<1 \mathrm{~cm})$. A method is needed for removing this surface layer in a cost effective way that minimizes the total volume of waste being produced.

Most candidate removal processes rely on mechanical techniques for removing the surface layer. Hitting the surface with either chisels or steel shot are effective for surface removal but often generate large amounts of dust. As a result, water is often used to wet the surface to reduce dust generation. The wetting of the surface can force soluble contamination into the sub-surface layer and also increases the volume of waste that needs to be processed because of the volume of water used in the process. In addition, the impact of the surface by the chisel or shot can drive contamination deeper into the concrete. A microwave heating process avoids these problems.

ORNL has developed a microwave process for removing contaminated surface layers of concrete.[15] The microwaves are used to heat the concrete and the free water present in the concrete matrix. The water can be quickly turned to steam that will induce a localized pressure gradient that results in a bursting of the surface layer. The debris that is produced by the burst can then be removed by a vacuum system. This technique has been shown to work at a variety of microwave frequencies ranging from $896 \mathrm{MHz}$ to $18 \mathrm{GHz} .[16,17]$ Because of the strong absorption, the

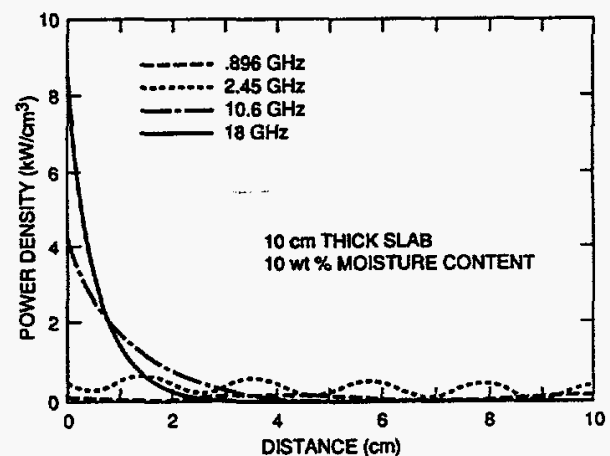

Fig. 9 Penetration depth as a function of frequency. higher frequencies concentrate the microwave energy in the surface layer, as shown in Fig. 9. This strong absorption layer allows only the top few millimeters of concrete to be affected by the microwaves and keeps the amount of generated waste to a minimum.

A mobile system for concrete removal has been demonstrated and is shown schematically in Fig. 10. The system consists of a large central enclosure and a mobile cart. The central enclosure contains the controls and power supplies, while the cart contains the microwave tube $(15 \mathrm{~kW})$, waveguide system, vacuum system, and drive system. The operating frequency is $18 \mathrm{GHz}$. The cart is tethered to the central enclosure via $30 \mathrm{~m}$ of water lines and power cables. A patented microwave applicator is used to direct the microwaves to the surface over a large area $(10 \times 14 \mathrm{~cm})$ with low microwave leakage. A vacuum system is also connected to the applicator to allow for the removal of the concrete debris as it is being removed from the surface. In addition, there is a CCD camera attached to the applicator that allows for real-time video feedback of the surface removal 
process. The system has been used to remove concrete under a variety of surface conditions, including oil soaked surfaces, painted surfaces, and surfaces containing metal anchors. The surface layer trench that is removed in one pass is typically $9-10 \mathrm{~cm}$ wide and $0.4-0.5 \mathrm{~cm}$ deep. The cart speed is controllable up to $1.1 \mathrm{~cm} / \mathrm{s}$, and typical removal rates are $40 \mathrm{ft}^{2} /$ hour. A new system with a robotic applicator arm capable of removing concrete from vertical surfaces is currently under development.

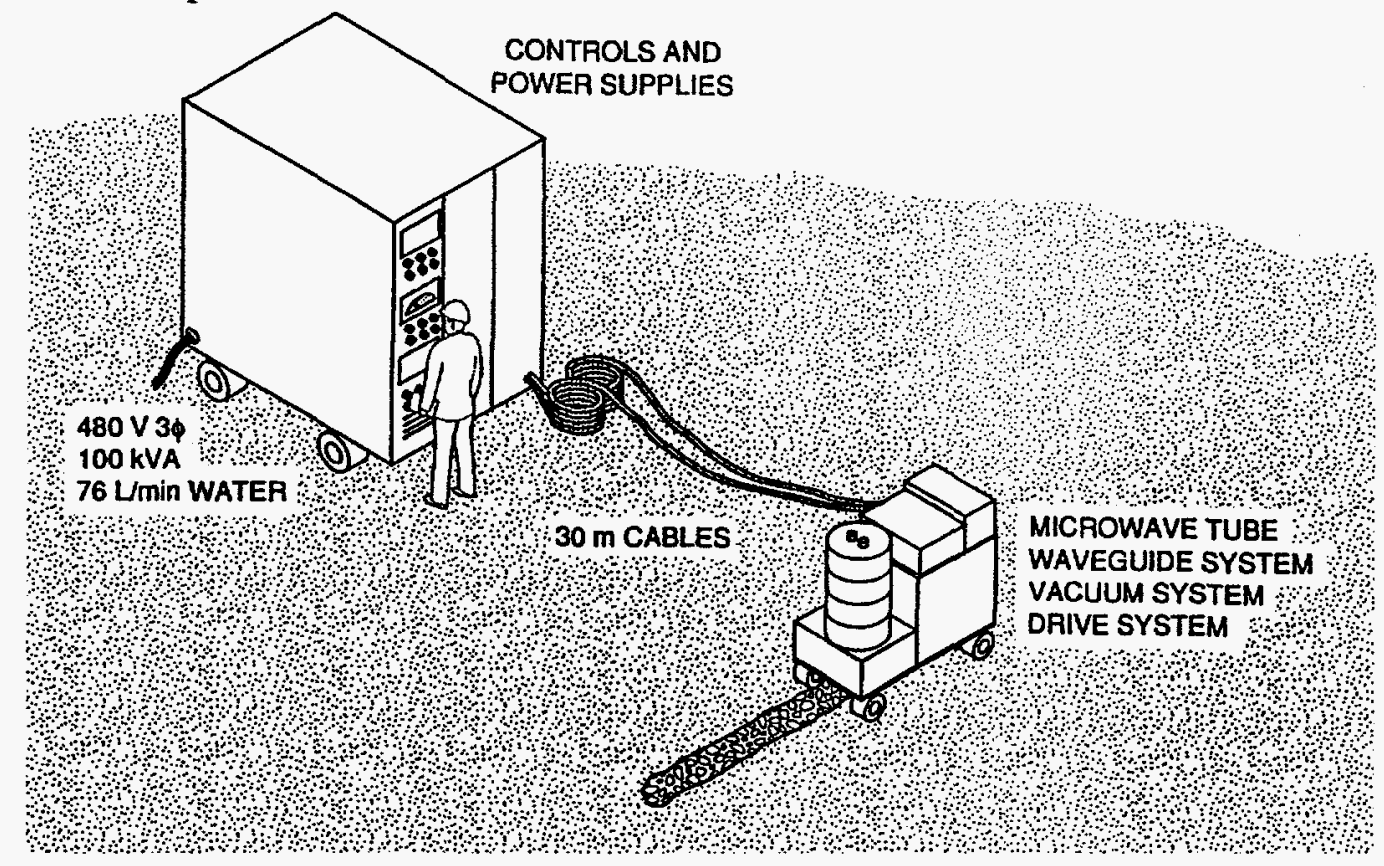

Fig. 10 Schematic of the mobile microwave decontamination system.

\section{SUMMARY}

Several application areas of rf and microwave technology have been discussed. The sintering of ceramics at frequencies ranging from $38 \mathrm{MHz}$ to 28 $\mathrm{GHz}$ has been demonstrated. In the area of plasma processing, the effects of processing parameters and boundary conditions on the energy of the ions at the substrate surface has been shown. The decontamination of concrete surfaces with microwaves has been shown to be an effective method for removing the top few $\mathrm{mm}$ of concrete while minimizing secondary waste production. There are several other areas where we are applying rf and microwave technology, including the processing of wood, microwave repair of asphalt surfaces, thin film deposition of diamond and silicon, and in-drum vitrification of chemical and other hazardous wastes. These are just a few of the many areas where rf and microwave technology can be applied outside of fusion research. 


\section{REFERENCES}

[1] Microwaves: Theory and Application in Materials Processing II, edited by D. E. Clark, W. R. Tinga, and J. R. Laia, Jr., Ceramic Transactions 36 (1993).

[2] Microwave Processing of Materials $I$, edited by M. F. Iskander, R. J. Lauf, and W. H. Sutton, Materials Research Society Symposium Proceedings, Vol. 347 (1994).

[3] W. H. Sutton, Ceram. Bull. 68 (2) 376-386 (1989).

[4] A. R. von Hippel, Dielectric Materials and Applications, edited by A. R. von Hippel, Technology Press of MIT/John Wiley \& Sons, New York, p.12 (1954).

[5] J. B. O. Caughman, D. J. Hoffman, F. W. Baity, M. A. Akerman, S. C. Forrester, and M. D. Kass, Ceramic Transactions (to be published).

[6] H. D. Kimrey, J. O. Kiggans, M. A. Janney, and R. L. Beatty, Microwave Processing of Materials II, Materials Research Society Symposium Proceedings, Vol. 189 , p. 243 (1991).

[7] M. D. Kass, et al., Ceramic Transactions (to be published).

[8] C. E. Holcombe, N.L. Dykes, and M.S. Morrow, "Thermal insulation for high-temperature microwave sintering operation and method thereof," U.S. Patent Application in Progress (1993).

[9] C.E. Holcombe and N.L. Dykes, Ceramics Transactions 21, p. 375 (1991).

[10] Papers from the Second Workshop on High Density Plasmas and Applications, J. Vac. Sci. Technol. B, Vol. 12 (1) (1994), pp. 454-511.

[11] J. Hopwood, et al., J. Vac. Sci. Technol. A, Vol. 11 (1), Jan/Feb 1993, p. 152

[12] W.M. Holber and J. Forster, J. Vac. Sci. Technol. A, Vol. 8 (5), Sep/Oct 1990, p. 3720

[13] Y.H. Shing, Solar Cells, 27 (1989) 331-340.

[14] J. B. O. Caughman, to be submitted to J. Vac. Sci. Technol. A, 1995.

[15] T.L. White, et al., Proceedings of the 21st American Nuclear Society Symposium on Waste Management, Tucson, Arizona (March 1995).

[16] H. Yasunaka, et al., Proceedings of the International Decommissioning Symposium, Oct. 4-8 (1987) pp.109-115.

[17] D.L. Hills, EUR 12185EN, Commission of the European Communities, Brussels (1989).

\section{DISCLAIMER}

\footnotetext{
This report was prepared as an account of work sponsored by an agency of the United States Government. Neither the United States Government nor any agency thereof, niability or responsiemployees, makes any warranty, express or implied, or assumes any legal apparatus, product, or bility for the accuracy, completeness, or usefulness of any informately owned rights. Referprocess disclosed, or represents that its use would not infringe price by trade name, trademark, ence herein to any specific commercial product, process, or sor imply its endorsement, recommanufacturer, or otherwise does not necessarily constitu or imply its ency thereof. The views mendation, or favoring by the United States Government or any agency thect those of the and opinions of authors expressed herein do no

United States Government or any agency thereof.
} 